\title{
Case of Endoscopic Surgical Treatment of Thoracic Arachnoid Cyst
}

\section{Roman Khalepa* and Yuliy Kubetskiy}

Spinal Neurosurgical Department, Federal Center of Neurosurgery, Novosibirsk, Russia

*Corresponding author: Roman Khalepa, Spinal Neurosurgical Department, Federal Center of Neurosurgery, Nemirovicha-Danchenko, Str. Bld 132/1, Russia, Tel: +7-913-382-22-05, Fax: +7-(383)-349-83-04

\begin{abstract}
Spinal arachnoid cysts are the benign intradural extramedullary lesions that usually occur at the thoracic region. Such cysts can cause compression of spinal cord with symptoms of myelopathy. The diagnosis is clinical and radiological with the use of MRI. Nowadays there are some surgical options to eliminate compression of spinal cord: laminectomy and total removal of the arachnoid cyst, puncture aspiration, cyst fenestration, cystoperitoneal shunting. Each of these options can be used in arachnoid cyst surgery and has its own advantages, disadvantages and indications. Currently, there is a general trend to minimize surgical trauma and to use of minimally invasive techniques. In the clinical case we reported surgical treatment of arachnoid cyst Th4-6 with myelopathy. Using the minimally invasive endoscopic method to perforate the walls of the cyst and to communicate its cavity with the subarachnodial space, we have got a good clinical result, which was followed up for 1 year after the operation.
\end{abstract}

\section{Keywords}

Spinal arachnoid cyst, Surgical treatment, Endoscopic technique

\section{Abbreviations}

MRI: Magnetic Resonance Imaging

\section{Introduction}

Spinal arachnoid cysts are the benign rare intradural extramedullary lesions. They can cause compression of the spinal cord and account for about $1-3 \%$ of all primary spinal cord lesions [1]. Possible causes of cysts are congenital formation of arachnoid diverticulum of the posterior arachnoid septum Schwalbe (primary cysts) or secondary defects of arachnoid membrane after injury [1], as a result of neoplasms, arachnoiditis or after lumbar puncture or surgery [2,3]. Although the mechanism of the cyst size increasing is still unclear, the cause of cyst growth is probably a valve mechanism that prevents the outflow of cerebrospinal fluid from the cyst cavity, which leads to increased pressure in its cavity and gradual growth [4]. Clinical symptoms of the thoracic arachnoid cysts are different from an asymptomatic and nonspecific local pain to myelopathy as a result of spinal cord compression. Diagnosis is usually made by MRI in patients with permanent local pain or progressive myelopathy $[2,5]$. MRI as a rule reveals dorsal location of the arachnoid cysts that causes compression of a spinal cord. The signal characteristics of the arachnoid cyst are equal to the cerebrospinal fluid [6]. More often, spinal arachnoid cysts are found at the thoracic spine region (65\%), less often in the lumbar and lumbosacral regions (13\%), in the sacral (6.6\%) and even less often in the cervical spine (3.3\%) [7]. The managing of arachnoid cysts depends on the symptoms that they cause. In the case of asymptomatic cysts, observation is usually prescribed. In case of neurological deficit progression, various options for surgical treatment are used. The tactics of surgical treatment are still the subject of discussion. Standard surgical treatment is laminectomy and total removal of the arachnoid cyst with dural suturing [7]. In cases of giant cysts, such surgical procedure is a traumatic intervention and can lead to progressive kyphotic deformity $[5,8]$. In cases of small cysts without communication with the subarachnoid space, puncture aspiration of the cyst fluid is possible [1]. Another surgical option for giant and segmented cysts is the cyst fenestration to make a communication between the cyst cavity and the subarachnoid space [5]. A rare 
type of surgical procedure in cases of arachnoid cysts is the cystoperitoneal shunting as a palliative intervention $[9,10]$. Nowadays, there are separate publications of endoscopic minimally invasive techniques for surgical treatment of arachnoid cysts [7].

The purpose of this article is to present a clinical case of a dorsal arachnoid cyst and use of endoscopic technique for arachnoid cyst surgery with good result.

\section{Clinical Case Presentation}

Patient N., 46-years-old, complained of discomfort and sense of burning in the thorax, behind the sternum, weakness in the legs and uncertain gait.

Patient had been worrying for complaints during the year before admission to our clinic. The neurological examination revealed cervical myelopathy: Hypertone (Aschworth 2) and hyper reflection in the lower extremities. No objective muscle weakness, sensory and urinary disturbances was found.

MRI revealed intradural extramedullary lesion on Th4-6 that makes a dorsal compression of spinal cord. The content of the formation is isointense to the cerebrospinal fluid (Figure 1).

Surgical treatment was performed. A $4 \mathrm{~cm}$ long midline incision was made at the Th4-5. Resection of
Th4, Th5 lamina with excision of the yellow ligament was made. The $5 \mathrm{~mm}$ incision of the duralsac was made. A flexible $2.8 \mathrm{~mm}$ endoscope (Figure 2) with working channel for a monopolar electrocauter and micro forceps was inserted into the cavity of the arachnoid cyst.

The cavity of the arachnoid cyst was revised - no communication of the cyst with the subarachnoid space was revealed. Perforation of the upper and lower pole of the cyst was made with a monopolar coagulator. Thus, communication of the cyst with the subarachnoid space is achieved (Figure 3).

There was no burning pain in the thorax after the surgery. There was no gain of neurological deficit. During a year patient noted an improvement in gait.

The patient was followed up for 1 year after surgery. According to MRI, there is no compression of the spinal cord, the arachnoid cyst has significantly decreased (Figure 4). There was no pain in the chest and no symptoms of myelopathy.

\section{Conclusions}

The use of video scope to perforate the walls of an arachnoid cyst allows to minimize surgical trauma with good functional and clinical results.
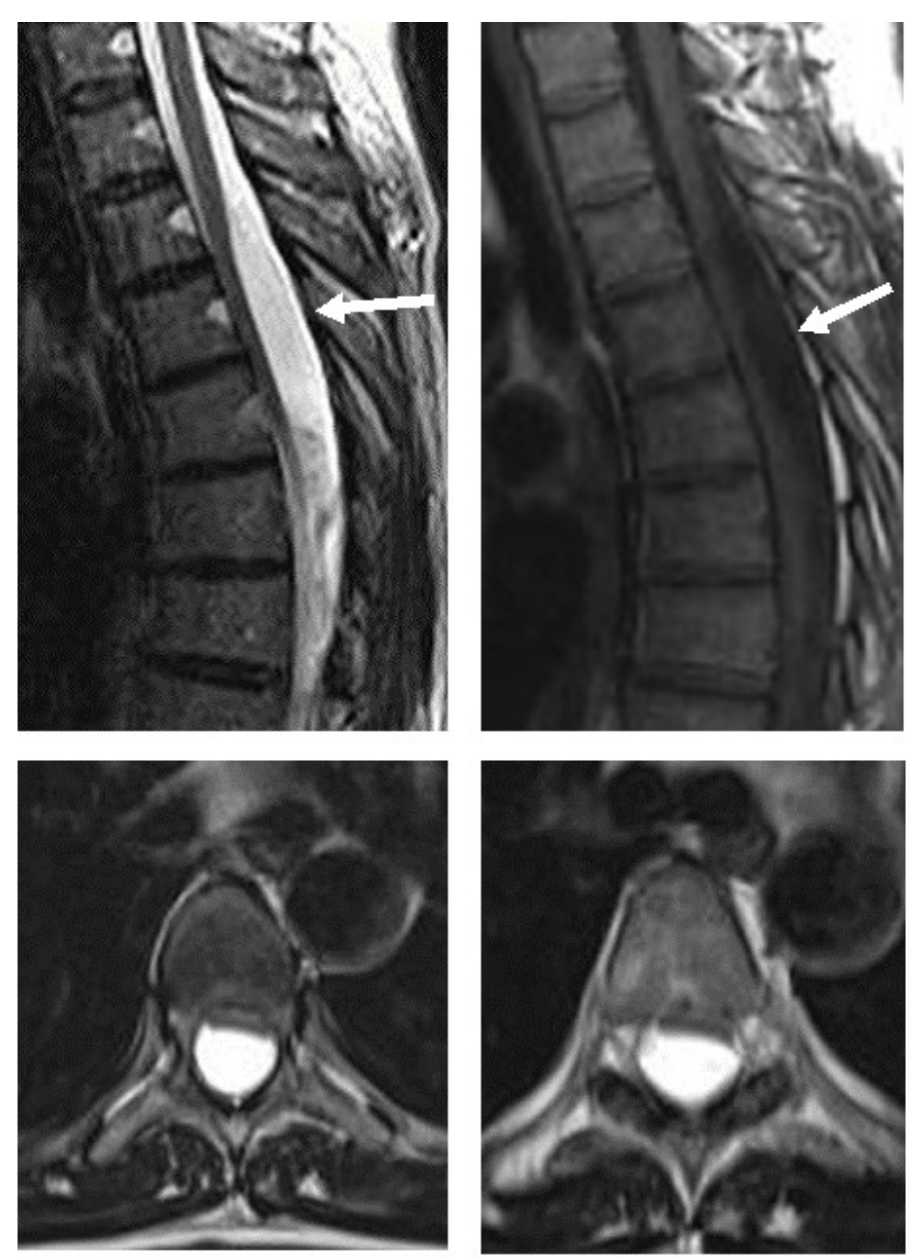

Figure 1: MRI before surgery. Sagittal and axial slices of T2 and T1 weighted MRI. 


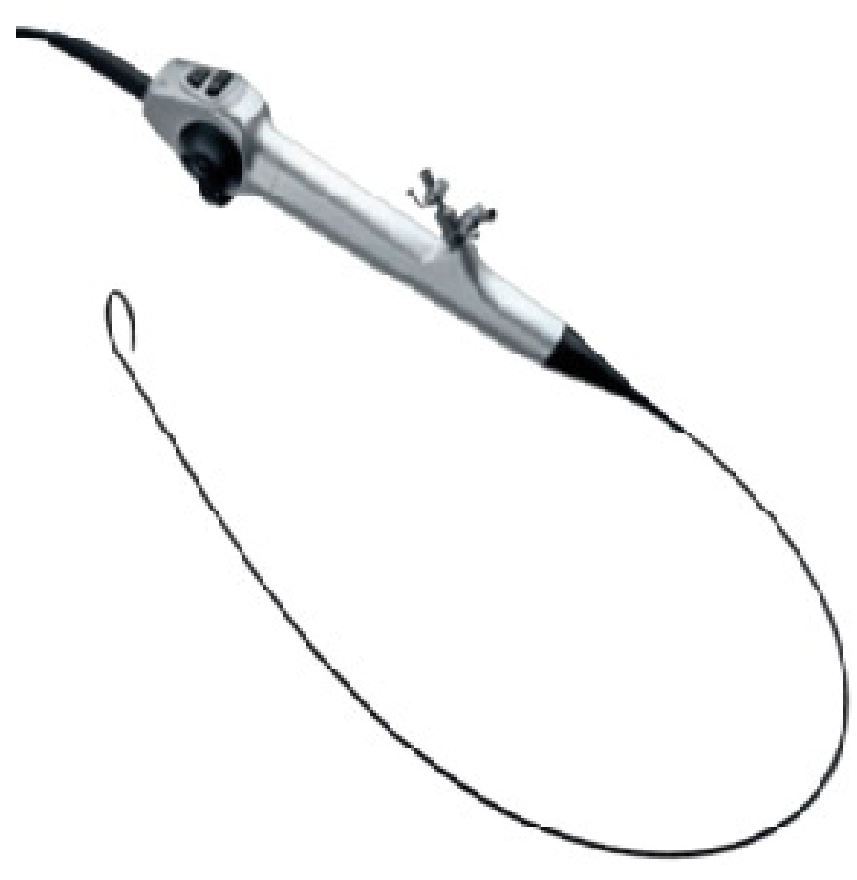

Figure 2: Video scope.

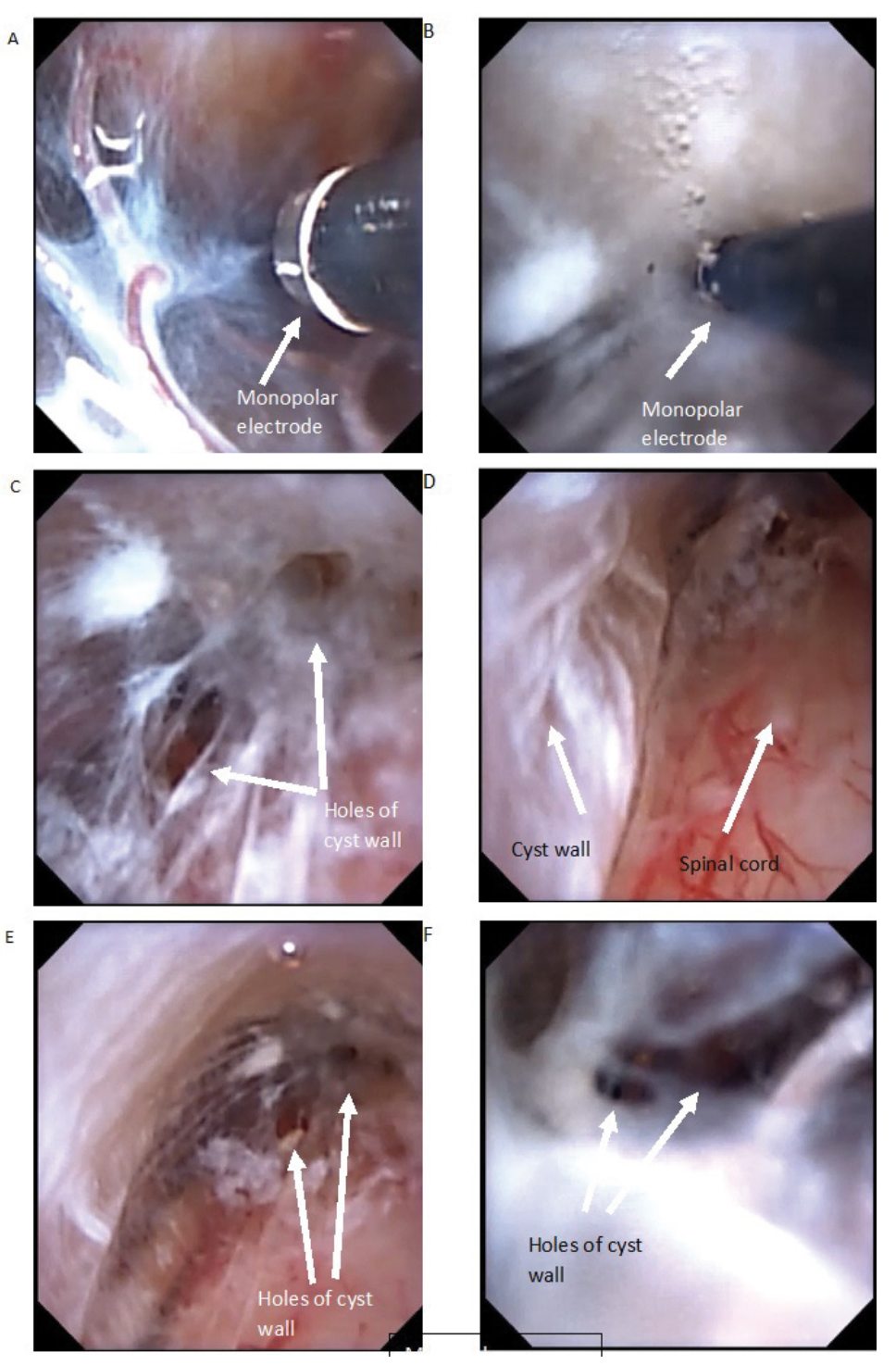

Figure 3: Intraoperative photo (A) Cranial wall of arachnoid cyst. Monopolar electrode; (B) Cyst wall penetration with monopolar electrode; (C,E,F) Holes after penetration; (D) Dorsal wall of arachnoid cyst and dorsal surface of spinal cord. 
A
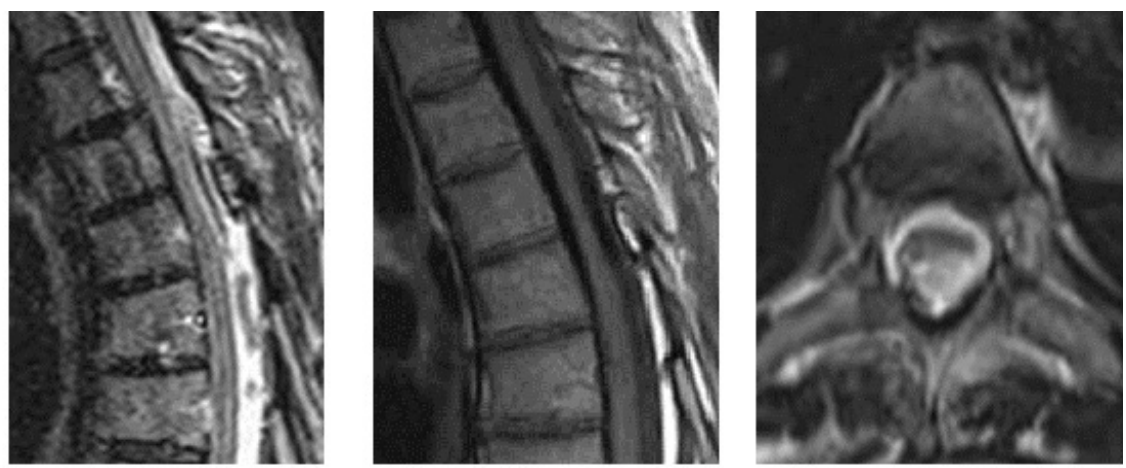

B
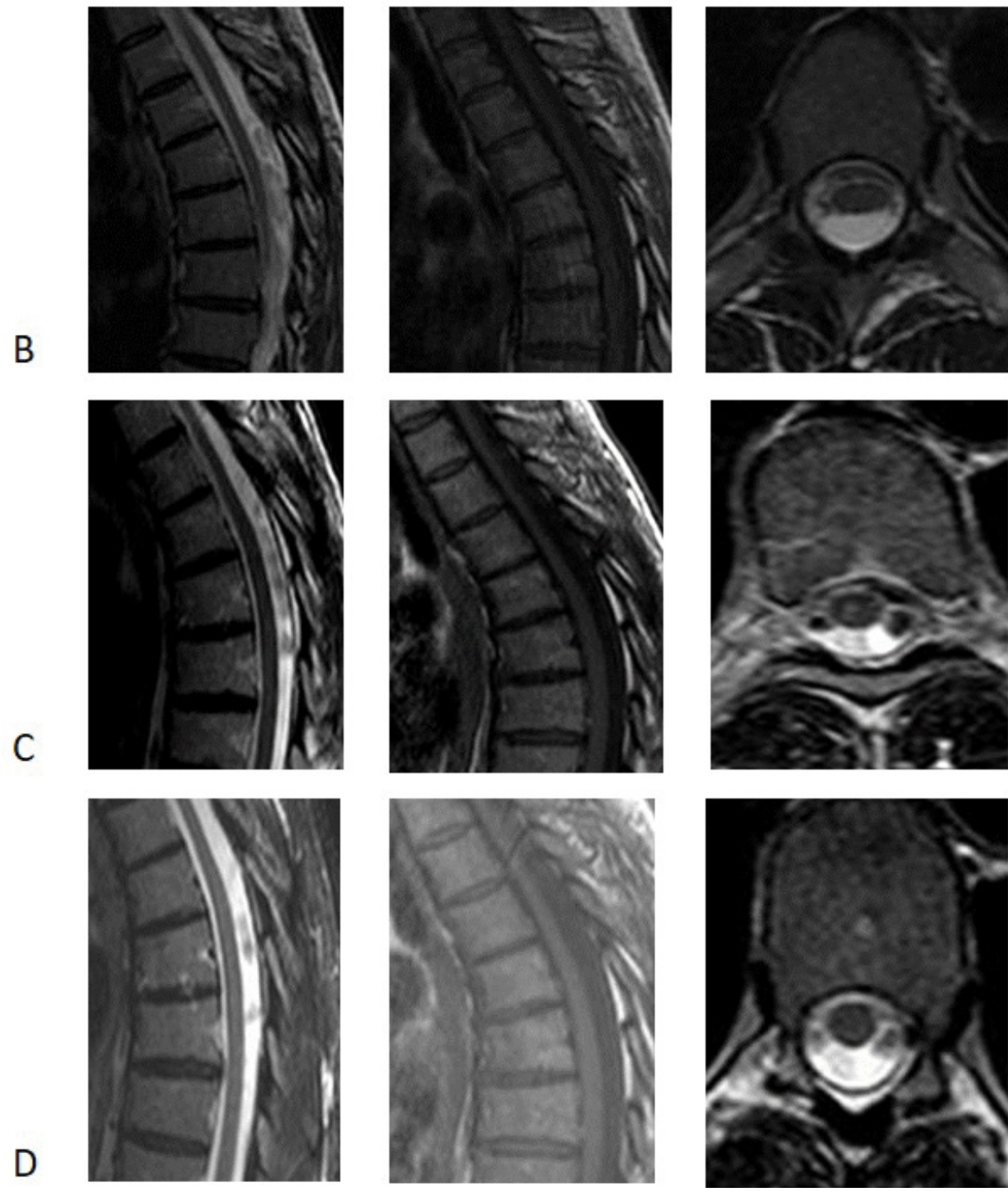

Figure 4: A) MRI the day after surgery; B) MRI in 3 months after surgery; C) MRI in 6 months after surgery; D) MRI in 12 months after surgery.

\section{Financial Support}

No sources of support.

\section{Conflict of Interests}

There is no conflict of interests.

\section{References}

1. Schmutzer M, Tonn JC, Zausinger S (2020) Spinal intradural extramedullary arachnoid cysts in adults-operative therapy and clinical outcome. Acta Neurochir (Wien) 162: 691-702.

2. Ebot J, Domingo R, Ruiz Garcia H, Chen S (2020) Intradural thoracic arachnoid cyst fenestration for spinal cord compression: A case illustration and video demonstration. Cureus 12: e6572.

3. Nath PC, Mishra SS, Deo RC, Satapathy MC (2015) Intradural spinal arachnoid cyst: A long-term postlaminectomy complication: A case report and review of the literature. World Neurosurg 85: 367.e1-367.e4.

4. McCrum C, Williams B (1982) Spinal extradural arachnoid pouches. Report of two cases. J Neurosurg 57: 849-852.

5. Petridis AK, Doukas A, Barth H, Mehdorn HM (2009) Spinal cord compression caused by idiopathic intradural arachnoid cysts of the spine: review of the literature and illustrated case. Eur Spine J 19: S124-S129. 
6. French $\mathrm{H}$, Somasundaram A, Biggs $\mathrm{M}$, Parkinson $\mathrm{J}$, Allan R, et al. (2017) Idiopathic intradural dorsal thoracic arachnoid cysts: A case series and review of the literature. J Clin Neurosci 40: 147-152.

7. Funao $\mathrm{H}$, Nakamura $\mathrm{M}$, Hosogane $\mathrm{N}$, Watanabe $\mathrm{K}$, Tsuji T, et al. (2012) Surgical treatment of spinal extradural arachnoid cysts in the thoracolumbar spine. Neurosurgery 71: 278-284.

8. Takagaki T, Nomura T, Toh E, Watanabe M, Mochida J (2006) Multiple extradural arachnoid cysts at the spinal cord and cauda equina levels in the young. Spinal Cord 44: 59-62.

9. Bellavia R, King JT Jr, Naheedy MH, Lewin JS (2000) Percutaneous aspiration of an intradural/extradural thoracic arachnoid cyst: Use of MR imaging guidance. J Vasc Interv Radiol 11: 369-372.

10. Spiegelmann R, Rappaport ZH, Sahar A (1984) Spinal arachnoid cyst with unusual presentation. Case report. J Neurosurg 60: 613-616. 